\title{
Study on the Current Situation and Application of Fresh Agricultural Products Sales Model
}

\author{
Jie Hu, Na Zhang*, Wenzhao Liu, Juanjuan Shan \\ Computer and the Information Engineering Institute, Beijing University of Agriculture, Beijing, China \\ Email address: \\ 1143644042@qq.com (Jie Hu), zhangna@bua.edu.cn (Na Zhang),975193784@qq.com(Wenzhao Liu), 957249937@qq.com (Juanjuan Shan) \\ ${ }^{*}$ Corresponding author
}

To cite this article:

Jie Hu, Na Zhang, Wenzhao Liu, Juanjuan Shan. Study on the Current Situation and Application of Fresh Agricultural Products Sales Model. Science Journal of Business and Management. Vol. 4, No. 6, 2016, pp. 194-198. doi: 10.11648/j.sjbm.20160406.13

Received: November 7, 2016; Accepted: November 28, 2016; Published: December 7, 2016

\begin{abstract}
At present, fresh agricultural products have begun to take the scale of industrialization, the majority have been in full accordance with high yield and high quality, efficient and safe production requirements, but due to the characteristics of fresh agricultural products, more and more attention have been aroused, the traditional marketing model is facing a bottleneck, the various aspects of new agricultural business sales models have been continuously improved. In this paper, we have analysed the traditional sales model of fresh agricultural products to find some existing thorny problems and compared with current network sales model which is on the rise and more and more popular, on the one hand, it shows the superiority of the sales network, on the other hand, Analyses were conducted on the the existing network environment in this sales model; at the same time, to carry out investigation of the present situation about fresh agricultural products and consumer markets, we are putting forward to this paper which could make a little bit significance when related sales platform optimizes the fresh agricultural products sales model.
\end{abstract}

Keywords: Fresh Food, Sales Model, Status, Application, Development Countermeasures

\section{Introduction}

Compared with other products, with fresh, perishable variety and multi-level characteristics of fresh agricultural products, some fresh food directly flow into the circulation of market trade, some will be in circulation after processing. First of all, the fresh food in the sales process, transportation, storage and sales must go through 3 stages, and the fruit and vegetable picking is still living, assimilation basically stopped, the main metabolism is respiration, is closely related to physiological and biochemical processes, and restrict the change of its physiological and biochemical can affect the quality of fruits and vegetables. Therefore, keep the quality of fresh food is also a focus problem to acquire high cost during transportation, storage and sales process. But the traditional sales model is often due to too many middlemen, and too much human, material and financial resources, so that the cost of fresh agricultural products increased significantly, but the quality is declining. Secondly, not only reflects the species beyond count fresh food, such as fresh vegetables, fresh fruit, fresh aquatic products, livestock and poultry live and fresh meat, eggs and milk, there are many levels, generally have excellent quality, international level etc.

Because low quality of the agricultural producers and social information system is not perfect and other factors, farmers on the later production arrangements tend to rely on the market information, but because of the information asymmetry, there are problems of excess production capacity and supply phenomenon, these two phenomena often appear periodically. On the one hand, the excess supply caused by market competition, decline of fresh agricultural product prices, farmers suffered losses; on the other hand, a round of excess supply, often accompanied by a lack of supply, industry volatility, industry chain related to the main loss. At the same time, follow the trend of production of the phenomenon also leads to the production of supply showed cyclical fluctuations, coupled with fresh storage facilities, backward agricultural products cold chain logistics technology, low in the process of transportation and circulation of various decay loss and other reasons, the fresh agricultural products logistics cost remains high, the circulation efficiency is reduced, which also increases the fresh agricultural products cost of sales.

In view of the characteristics of fresh agricultural products 
and farmers own sales, more and more obvious that the traditional sales model must rely on the twenty-first Century network sales platform to improve the information system, broaden farmers sales thinking, the following specific analysis for sales model of fresh agricultural products in the traditional and emerging application mode.

\section{Application Analysis of 1 Fresh Agricultural Products Sales Model}

\subsection{Traditional Sales Model}

According to the form of fresh agricultural products supply chain is different, each of the supply chain has played an important role in the core link, around the core link to form the chain structure of fresh agricultural products supply chain The traditional fresh agricultural products sales model based on the network chain structure shows a different mode of operation, now there are three traditional patterns to fresh agricultural products wholesale market, fresh agricultural products processing enterprises, fresh agricultural products of large retail enterprises as the core. The first mode is dominant in the fresh agricultural products circulation form, wholesalers can be divided into a wholesaler, two wholesalers, between producers and consumers through multi-level wholesale complete supply chain process; second models of whole supply chain process is divided into fresh agricultural products, raw material supply system of fresh agricultural products processing system and fresh agricultural product distribution system, this model ensures the fresh agricultural products processing enterprises have a stable supply, the relative reduction of intermediate links, fresh agricultural products supply chain in the value-added process at the end of a pattern, leading power began to shift from manufacturers to retailers of fresh agricultural products industry chain core in, which leads to the original manufacturer as the core leading sales model to large retailers as the core leading sales mode.

There are some problems in the application of the traditional sales model in the process of operation:

First, the high cost of operation. Small scale operation of the supply chain and the market behavior are not accurate, and other acts, resulting in higher transaction costs. At the same time, because of the fresh agricultural products production and sales are often separated, repeatedly, aging vulnerability plus fresh agricultural products, the need to repeatedly test in the process to sell in improving execution cost.

Second, extensive sales. The low level of production organization brings some disadvantages, such as lead to market confusion, business class is low, is not conducive to business process supervision, product quality uneven, transaction way backward, sometimes happen disorderly competition etc..

Third, the degree of product standardization is low. Blind cultivation, fresh agricultural products of large retail enterprises have strict standards for purchasing specifications of fresh agricultural products, but each company to purchase standard of fresh agricultural products developed are not the same, the same product in a family enterprise through the acceptance, but may be another cannot pass. At present, the more common is the wholesalers to the fields acquisition, and then get the wholesale market, the parties to the transaction is mainly with the eyes, hands, there is no standard.

\subsection{Fresh Agricultural Products Electricity Suppliers Sales Model}

With the development of science and technology, the network has brought people a more convenient way of life, the network has gradually become an indispensable part of agricultural production. Problems in the traditional sales model of fresh agricultural products, often concentrated in the construction of sales channels, the emergence of network electricity suppliers, to some extent, ease the pressure on this area.

Fresh agricultural products e-commerce platform [1] is a new open platform of supply chain management in the Internet, networking and fresh agricultural products logistics information network [2-4], for the fresh agricultural products logistics supply chain will create a fresh agricultural products logistics information dissemination, exchange, sharing, collaborative work environment. We must first use of network resources and advantages of mature high-speed information transfer, further optimization of fresh agricultural products logistics process, and accurately transfer the information to the government and the cultivation of farmers, farmers of the state and the better control and planning. Secondly, through the Internet of things to the fresh agricultural products supply chain of all aspects of real-time monitoring, management of the logistics system, and fresh agricultural products in the supply chain of all aspects of information analysis and prediction. Finally, to make full use of the function of the fresh agricultural products logistics information network, strengthen the traceability, early warning and information release, establish the stage of fresh agricultural products quality and safety information platform [5]. Through the construction and integration of the 3 network platforms, it can improve the efficiency and reduce the errors.

Now, the agricultural electronic commerce has also formed a new business model for their own - $\mathrm{O} 2 \mathrm{O}$ (online to offline), that is, online consumption, online under the enjoyment of services. At present, Tmall [6], Jingdong, one shop business platform such as "farming", "Lenovo Jia" and "Tian Mu" represent 3 utilization of agricultural e-commerce platform [7] for fresh agricultural products transaction, they are promoting China's traditional agricultural industry with the transformation of the pattern of electronic commerce. The biggest advantage of these trading processes is to save a lot of middlemen and circulation time, and relying on professional logistics to reduce the loss of fresh agricultural products, to ensure the quality of products, reduce the cost. Especially like "professional enterprise dish steward of a class, directly created P2B2F mode (i.e. farmers + company + consumer) directly, eliminating the middleman, production, sales and service in one, set up fresh agricultural products sales platform comprehension. In addition, in order to avoid the phenomenon of fresh agricultural products oversupply, fresh 
agricultural products business platform to provide more market information, for farmers to reference, as a indicator of planting.

\section{Analysis on the Current Situation and Problems of 2 Fresh Agricultural Products Online Sales}

Research results: consumers and producers of Beijing city based on consumer survey on fresh agricultural products sales mode [8], results show that the purchase of fresh agricultural products on the Internet who only part of the vast majority of people are not willing to buy fresh agricultural products on the Internet, the main reason is: concerned about the safety of Online purchase of agricultural product safety [9], trade of the network not trust and logistics distribution system needs to be improved (Figure 1).

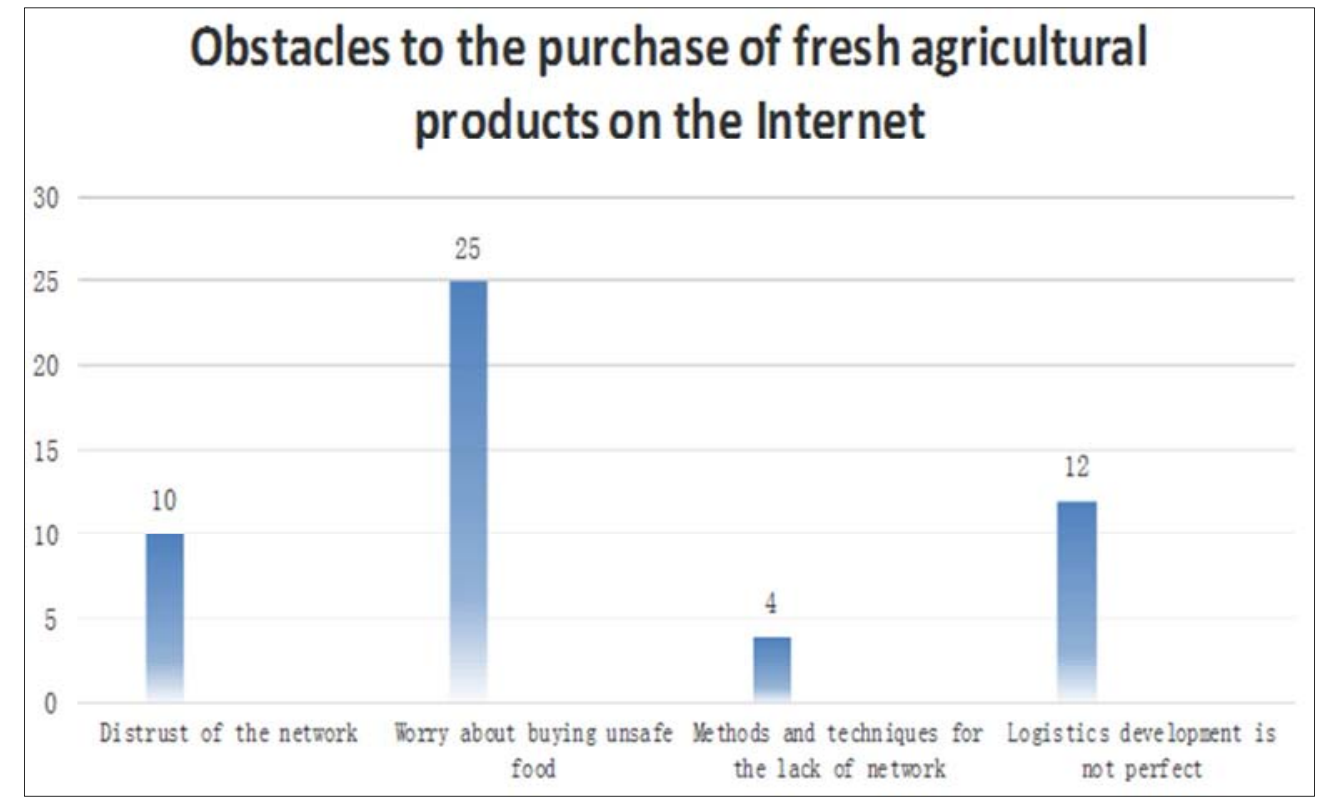

Figure 1. Online purchase of fresh agricultural products barriers.

After investigating the location of fresh agricultural products consumers purchase [10], it is found that the main consumers are more willing to buy in supermarkets and agricultural products outlets, only a part of the people are willing to buy online. (Figure 2).

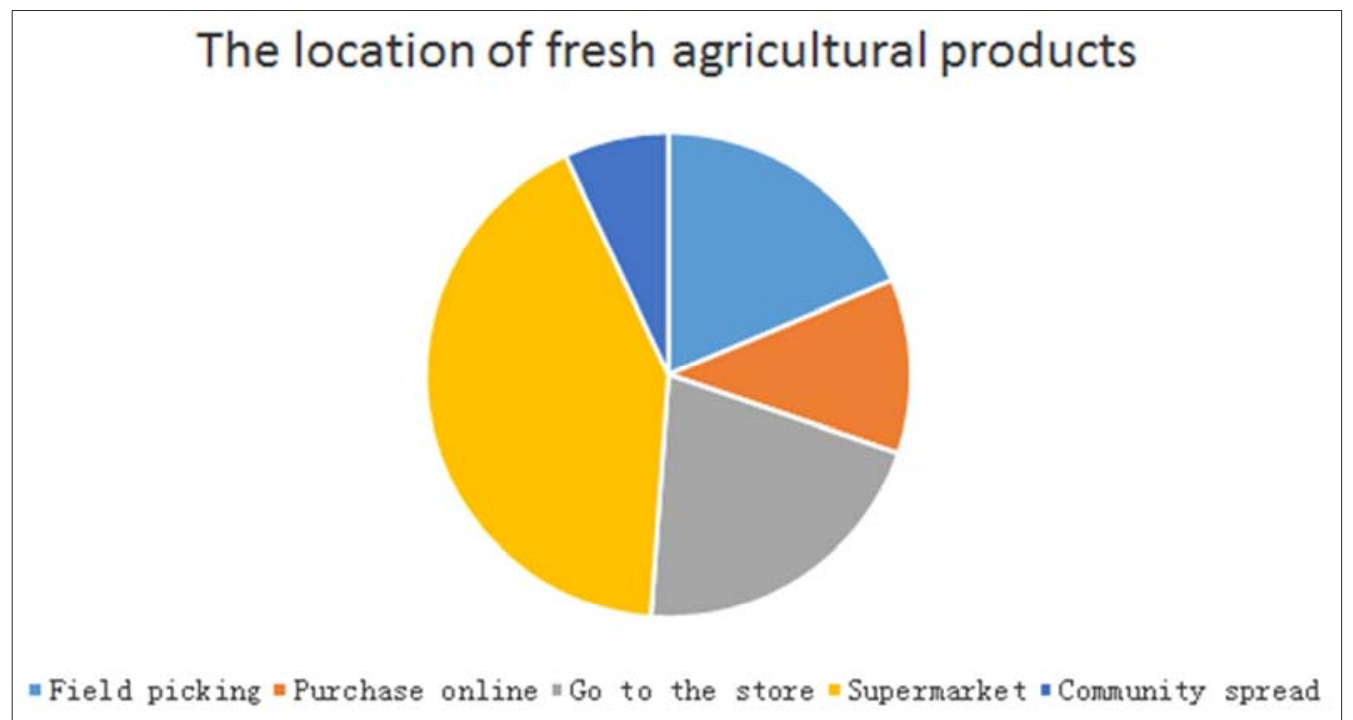

Figure 2. Place to buy fresh agricultural products.

The purchase of fresh agricultural products on the Internet people [11-12], they choose the main reason to buy fresh agricultural products on the Internet is because commodity prices and cheap online agricultural product variety, the region difference, only a small number of people think that the agricultural products is only suitable for online purchase (Figure 3). 


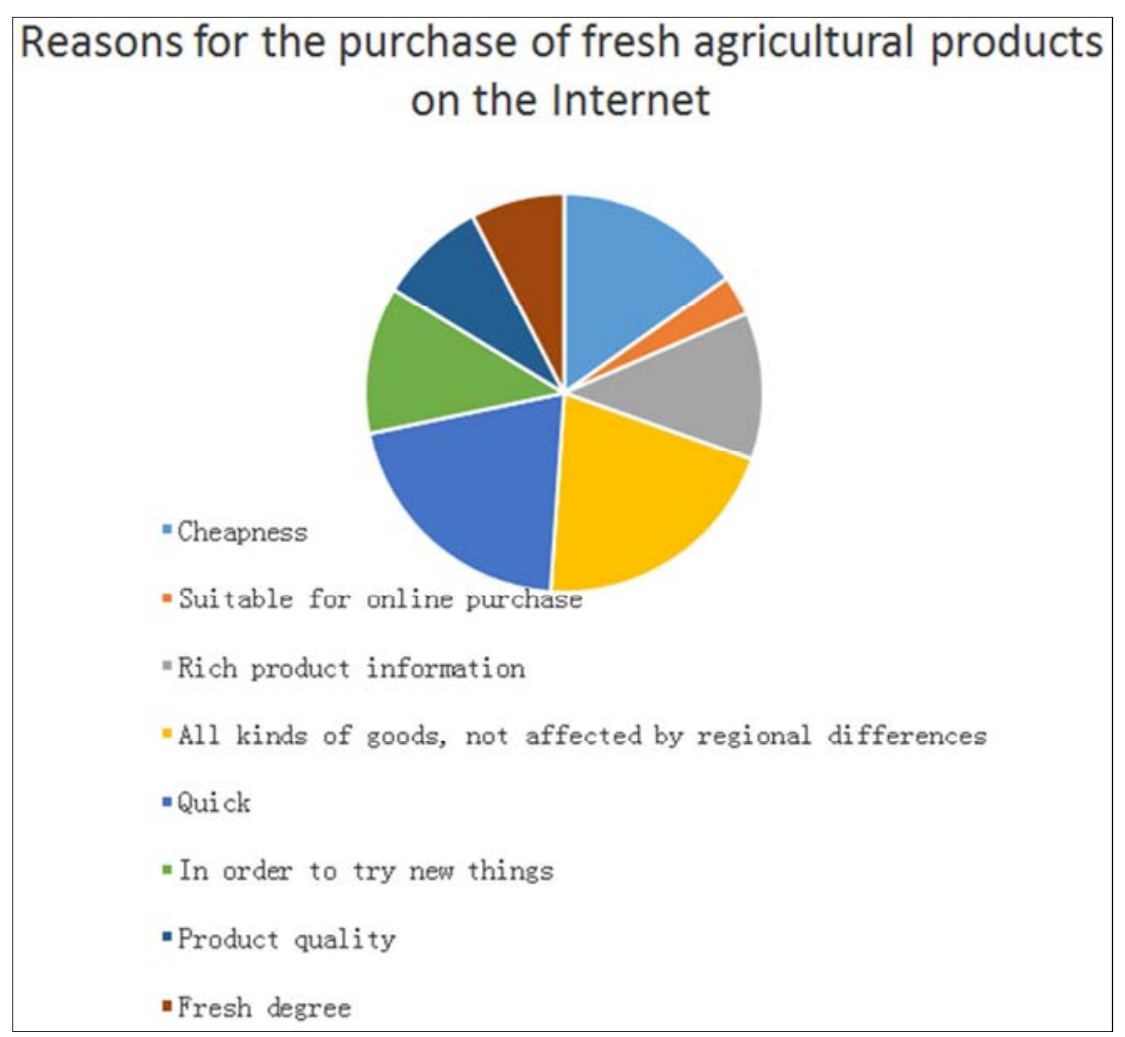

Figure 3. The reason for the purchase of fresh agricultural products on the Internet.

\section{Countermeasures and Suggestions on the Network Marketing Mode of Fresh Food Agricultural Products}

In view of the problems in the network marketing mode of China's fresh agricultural products, this paper puts forward the countermeasures from three aspects, which are the trust degree, the sales logistics system and the sales promotion channel:

First, for consumers of fresh agricultural products network security is not a problem of trust, agricultural enterprises have to establish a sound credit system to ensure that consumers and businesses will face the risk of transactions. Through the establishment of fresh agricultural product quality and safety traceability information platform, and gradually establish and improve the quality of fresh agricultural products can query, quality and safety traceability, product recall related systems. This is not only a strategy for enterprises to deal with the market situation, but also a new concept of fresh agricultural products logistics management under the background of high-tech. Through the whole process of fresh agricultural products quality supervision, the establishment of fresh agricultural products quality and safety warning system, thereby enhancing the competitiveness of fresh agricultural products in terms of quality and safety.

Second, the perfect logistics system is the guarantee of the effective implementation of the network marketing of fresh agricultural products. Fresh agricultural products market existing e-commerce model has $\mathrm{B} 2 \mathrm{~B}, \mathrm{~B} 2 \mathrm{C}$ and $\mathrm{C} 2 \mathrm{C}$, the 3 modes of supply and demand information asymmetry problem, to bring many inconvenience to customers. And now the B2B2C electronic commerce mode with the third party logistics center of electronic network as a platform, to understand the supply and demand sides timely and accurately, according to the adjustment scheme for the distribution of information, a good adjustment of seasonal and regional issues, to provide quality services and improve the logistics center economic benefit increased the added value of agricultural products, improve the credibility of the logistics center. This model makes the third party logistics enterprises, customers (farmers) and consumers (supermarkets) through electronic transactions between the supply and demand balance, reduce the cost of sales.

Third, fresh agricultural products publicity channels although many, but the TV advertising cost is too high, and the need to send brochures of manpower, and only a small range of promotion, we can promote the use of the Internet technology, the first is from the media marketing, including WeChat public number, and the circle of friends from the media Reds micro-blog; second is the conventional network promotion, including the forum and the top post, QQ group promotion, Taobao promotion, micro-blog, personal circle of friends APP promotion, promotional video, QQ space reprint, Baidu platform promotion and so on, not only greatly reduce the cost of publicity, but also the network information technology once again applied to agriculture. 


\section{Conclusion}

Brief analysis of fresh agricultural products and its characteristics in different sales model respectively through this paper, puts forward the existing traditional and new sales model in the process of operation, and further analysis of the impact of these problems, the limitations of each of the factors we were from the consumers of fresh agricultural products sales network mode trust, network sales model of the logistics system and fresh publicity channels and so on to make specific suggestions, hoping to optimize sales companies and sales platform sales model, in order to achieve fresh agricultural products sales model standardization and efficiency.

\section{References}

[1] Fengxu Wang, Jia Baoxian. Research on network marketing strategy of agricultural products under e-commerce environment [J]. Anhui agricultural science. 2012 (04).

[2] Guiping Wang. Study on the logistics operation of China's agricultural products under the electronic commerce environment [J]. Shandong agricultural science. 2011 (11).

[3] Xueqin Chen. Research on the development of electronic commerce of agricultural products in Inner Mongolia [D]. Inner Mongolia Agricultural University. 2012Clerk Maxwell, Treatise on Magnetism, 6rd ed., vol. 2. Oxford: Clarendon, 1989, pp.68-73.

[4] Shuo Yang. Study on the whole process of electronic commerce of fresh agricultural products $[\mathrm{J}]$. agricultural network information. 2010 (11) J. Young, A Technical Write, 5rd ed., vol. 9. Oxford: Clarendon, 2002, pp. 73.
[5] Hui Xie. Research on the mode and development trend of agricultural product network marketing [J]. science and technology entrepreneurship monthly. 2010 (09).

[6] Jing Hu. Analysis on the marketing strategy of Taobao's online merchants [J]. enterprise technology development. 2010 (8).

[7] Kaichi $\mathrm{Hu}$. On the construction of agricultural products marketing network system. Chinese collective economy [D].2009.28.

[8] Bai Shi. Problems of network marketing of agricultural products under the electronic commerce environment $[\mathrm{J}]$. economist. 2012 (07) K. Elissa, "Title of paper if known," unpublished.

[9] Hailong Wang. Research on the network marketing strategy of agricultural products in Anhui Province under the background of new rural construction [D]. Anhui University, 2010Y. Yorozu, M. Hirano, K. Oka, and Y. Tagawa, "Electron spectroscopy studies on magneto-optical media and plastic substrate interface," IEEE Transl. J. Magn. Japan, vol. 2, pp. 740-741, August 1987 [Digests 9th Annual Conf. Magnetics Japan, p. 301, 1982].

[10] Tiemin Liu, Zhou Jing. Learn from the United States experience to promote the rapid development of China's agricultural product network marketing $[\mathrm{J}]$. agricultural economy. 2012 (1).

[11] Zhengming Hu. The problems and Countermeasures of China's Internet marketing [J]. China's circulation economy.2002, (2): 49-52.

[12] Wenchuan Wang. Research on marketing strategy of agricultural products $[\mathrm{J}]$. Shanxi science and technology.2005 (3): $3-4$. 